\title{
Computação Ubíqua para apoiar a educação musical: explorações com o Makey Makey
}

\author{
Thiago Marcondes Santos ${ }^{1}$, Denise Filippo ${ }^{2}$, Mariano Pimentel $^{3}$ \\ ${ }^{1,3}$ PPGI-Programa de pós Graduação em Informática - Universidade Federal do Estado \\ do Rio de Janeiro (UniRio) Av. Pasteur 458, Térreo, Urca, 22290-240, Rio de Janeiro, \\ RJ, Brasil. \\ ${ }^{2}$ Escola Superior de Desenho Industrial (Esdi) - Universidade do Estado do Rio de \\ Janeiro (Uerj) R. Evaristo da Veiga, 95, Centro, 20031-040, Rio de Janeiro, RJ, Brasil \\ thiago.marcondeseuniriotec.br, dfilippo@esdi.uerj.br, \\ pimenteldunriotec.br
}

\begin{abstract}
Resumo. Aprender um instrumento musical está associado a horas de prática para aperfeiçoamento técnico e evolução musical do estudante, deixando fora desse processo muitos interessados que não podem se dedicar com tanto esforço. Esse contexto se deve às características físicas de cada instrumento e sua maneira particular de gerar o som. Com as novas tecnologias computacionais, como a computação ubíqua, outras formas de se gerar som possibilitam outras abordagens para a criação e educação musical. Este artigo descreve uma investigação do uso da computação ubíqua no contexto de sala de aula do ensino fundamental com intuito de promover a aprendizagem e a vivência de conceitos musicais. Num estudo de caso exploratório, um ambiente escolar foi transformado em um laboratório sonoro, cujos sons foram ativados a partir de contatos corporais já conhecidos dos estudantes, como o bater de palmas. Desta forma, a sala de aula se apresenta como instrumento musical coletivo, diminuindo as barreiras técnicas necessárias à execução musical.
\end{abstract}

\section{Introdução}

A lei 11.769/08, sancionada pelo então presidente Luiz Inácio Lula da Silva, estabeleceu a volta ao ensino de música obrigatório até 2012, quando todas as escolas deveriam estar adequadas às novas normas. Esta lei trouxe o aumento da demanda por profissionais da educação musical e também por estratégias e ferramentas didáticas que respaldem esse processo. É neste contexto que desenvolvemos a presente pesquisa: por meio de um estudo de caso, investigamos o uso da computação ubíqua para apoiar o professor em seu trabalho de intermediador entre o estudante e o conhecimento musical.

Atualmente a sociedade está iniciando a terceira era da computação, que é caracterizada pela situação em que cada pessoa possui vários dispositivos computacionais (Weiser,1991). O cenário visualizado por Weiser é de um mundo com dispositivos eletrônicos em todos os lugares (ubíquos), em grande quantidade, baratos, conectados em rede e que podem ser fixos ou móveis. Embutidos em objetos que cercam a vida cotidiana, como fogões, geladeiras, telefones, bicicletas, entre outros. Esses dispositivos estão presentes no local em que eles são necessários, sendo discretos visualmente e em seu comportamento, de forma a só atuarem quando necessário.

A sociedade vem se transformando e a Educação, em particular, é uma área com potencial para se beneficiar das possibilidades advindas com o paradigma da 
computação ubíqua. Nesta pesquisa investigamos como a escola pode usufruir das novas tecnologias computacionais para apoiar o ensino de música neste cenário da terceira era da computação. Alguns trabalhos relevantes na área de educação musical que utilizam novas tecnologias computacionais são discutidos na Seção 2.

Com o objetivo de diminuir as barreiras de execução técnica dos instrumentos tradicionais de forma a possibilitar um maior foco na aprendizagem dos conceitos musicais, elaboramos um artefato baseado em computação ubíqua e projetamos atividades educacionais para a utilização do artefato, apresentados na Seção 3.

A metodologia de pesquisa e as etapas realizadas para a coletas de dados são descritas na Seção 4. Na Seção 5 são apresentadas as análises sobre os resultados, e a Seção 6 conclui a análise dos dados e aponta estudos futuros sobre o tema.

\section{Ensino musical e computação ubíqua}

Nesta seção discutimos o ensino musical, o cenário das escolas brasileiras, trabalhos sobre computação ubíqua ligada à produção sonora e ao ensino de música e algumas possibilidades do uso destas tecnologias para a educação.

\subsection{0 ensino musical}

Todos os estudantes de música devem ser encorajados a participar de alguma forma do discurso musical, mesmo com diferenças na sua capacidade e talento técnico e instrumental (Rosen et al, 2013). Pensadores como Emile Dalcroze e Carl Orff, já na $1^{\text {a }}$ metade do século XX, apontavam novas direções para o ensino musical que até então era baseado num paradigma de execução de um instrumento orientada ao repertório clássico vigente e de ênfase ao virtuosismo instrumental. Tais procedimentos pedagógicos afastavam os estudantes da música e os direcionava para práticas técnicas dos instrumentos (Dalcroze, 1921). Dalcroze e Orff também defendiam o uso do corpo e do movimento através de gestos como intermediadores do processo de conhecimento musical dando suporte ao entendimento e assimilação do discurso musical (Shamrock, 2009).

Educadores como Orff buscavam facilitar a produção do som por parte dos estudantes utilizando instrumentos como o metalofone e o xilofone, que permitem a geração do som sem muito esforço. Adicionalmente, o fato de o xilofone ser construído com barras que podem ser retiradas possibilita configurar o instrumento para determinados exercícios que evitem erros por parte do estudante: por exemplo, é possível retirar barras deixando apenas o subconjunto específico de notas com as quais ele vai trabalhar em sala de aula. Evita-se assim problemas com questões de execução técnica como notas excedentes que podem induzir o estudante ao erro. Orff também defende que todo material que a criança já tenha em seu acervo de conhecimentos pode ser usado ao seu favor: as brincadeiras de palmas e cantos das crianças, além da própria métrica e ritmo da linguagem falada na infância, constituem um material muito rico para se abordar ritmos e outros elementos musicais (Campbel, 2008) (Shamrock, 2009).

\subsection{Cenário atual das escolas brasileiras}

O resumo técnico do censo escolar da educação básica de 2013 mostra que Brasil teve naquele ano 29.069.281 de matrículas no ensino fundamental, (Censo, 2013). Em relação à presença de computadores e internet nas escolas, os dados apresentados indicam que na rede pública, $82,3 \%$ dos estudantes têm acesso à internet e $80,6 \%$ têm 
acesso a laboratórios de informática. Na rede particular, os índices são 96,8\% e 75,6\% respectivamente (Censo, 2013).

Com as novas possibilidades ofertadas pela tecnologia, a educação da sociedade também se transforma e absorve as novas tendências. Exemplos significativos são as iniciativas OLPC (One Lap Top Per Child) desenvolvido pelo MIT (OLPC, 2005) e UCA (Um Computador Por Aluno, adaptado pelo MEC para as escolas brasileiras) (UCA, 2007). O uso de computadores e o maior acesso à internet nas escolas também indicam uma apropriação da escola brasileira das novas tecnologias computacionais.

$\mathrm{O}$ artefato que propomos nesse trabalho tem, assim, o potencial de atender a uma expressiva parcela da população estudantil brasileira, tanto em valores absolutos quanto relativos.

\subsection{Computação ubíqua e música}

A escola deve se adaptar e fornecer ao estudante maneiras de vivenciar a música e de poder se expressar através do discurso musical, sempre respeitando sua realidade cultural. Atualmente grande parte dos estudantes já absorveu as inovações tecnológicas do século XXI em seu cotidiano, por exemplo, por meio do uso de redes sociais e da produção e manipulação de textos, sons e vídeos. A computação ubíqua tem potencial para ser um elo entre a escola e a realidade cotidiana dos estudantes.

Existem diferentes pesquisas para a utilização de tecnologias envolvendo dispositivos móveis e objetos inteligentes para dar apoio à produção sonora e também à educação musical. Zhang et al. (2011) propõem o uso de um artefato para simular um instrumento tradicional como a guitarra elétrica ou o violão através de sensores e de um microprocessador fixados em uma vassoura.

Volpe et al. (2012) desenvolvem uma plataforma para a utilização de gestos como manipuladores do ambiente sonoro através de captação de imagens da movimentação de crianças. Em Rhen et al., (2012), uma mesa multitouch foi desenvolvida para que mais de um usuário pudesse interagir através de toques para a obtenção de sons sintetizados através de algoritmos que emulam instrumentos percussivos.

No trabalho de Zhou et al. (2011) é proposto um sistema que integra professor e alunos via smartphones com fones de ouvido, possibilitando diferentes configurações entre os estudantes para se produzir música, seja dividindo a sala em grupos que podem tocar isoladamente ou juntos, seja em modo de apresentação de toda a turma. Os pesquisadores isolam os alunos uns dos outros utilizando os fones de ouvido, portanto, os membros de um grupo podem praticar suas atividades musicais ouvindo uns aos outros e sem interferências dos demais grupos ou de sons do ambiente. Adicionalmente, eles também não geram som para o ambiente.

Esse trabalho difere dos demais pelo conjunto de características do artefato proposto: seu objetivo é educacional, ao contrário de Zhang et al (2011), Volpe et al (2012) e Rhen et al (2012), que são voltados para a execução de música. Diferentemente de Zhou et al. (2011), que supõe que os alunos tenham smartphones, nesse trabalho é concebido e desenvolvido um artefato que se insere no cenário atual da computação ubíqua de prover inteligência a objetos, que utiliza materiais facilmente encontrados no mercado e que possui baixo custo para que possa ser adquirido pelo professor ou pela escola. Adicionalmente, o artefato proposto busca evitar a necessidade de longo aprendizado técnico para a produção dos sons e, de acordo com as propostas de Dalcroze e Orff, está associado a atividades que utilizam o próprio corpo e o corpo de 
outros estudantes para a produção sonora. A possibilidade de produção sonora em grupo também possibilita atividades que seguem os princípios da aprendizagem colaborativa (Castro e Menezes, 2011).

\section{0 artefato}

Nesta Seção apresentamos o artefato proposto e requisitos das atividades educacionais de música para as quais ele oferece suporte. $\mathrm{O}$ artefato é um dispositivo eletrônico que foi denominado ASU (Ambiente Sonoro Ubíquo).

\subsection{Requisitos das atividades educacionais}

As atividades educacionais propostas nesse trabalho para serem usadas com o artefato têm os seguintes requisitos:

- Possibilidade de abordar elementos do discurso musical e de oferecer um espectro abrangente de sonoridades

- Maior facilidade de produzir e acionar sons em comparação aos instrumentos musicais tradicionais

- Criação de uma alternativa sonora não excludente aos instrumentos musicais tradicionais

- Possibilidade de instigar a participação dos estudantes

- Uso do corpo e gestos para o acionamento sonoro

- Colaboração entre os participantes

- Facilidade de reprodução da atividade por um professor com pouco conhecimento de computação e com recursos financeiros reduzidos

Foram pesquisadas diferentes tecnologias ubíquas para possibilitar uma alternativa aos instrumentos tradicionais, o uso do espaço da sala e os corpos dos estudantes através de simples gestos como o bater de palmas. A solução encontrada surgiu da conjugação do hardware Makey Makey (Makey Makey, 2015), do software soundplant (soundplant, 2015) e de pisos emborrachados, que atende aos requisitos de facilidade de reprodução e baixo custo e promove um cenário potencialmente instigante para os estudantes por fazer uso de novas tecnologias computacionais.

\subsection{O artefato ASU (Ambiente Sonoro Ubíquo)}

O dispositivo proposto, denominado ASU (Ambiente Sonoro Ubíquo) é composto de um software e um hardware que, combinados, possibilitam a produção sonora de forma simples e sem as demandas técnicas características dos instrumentos musicais tradicionais. O software soundplant é operado por uma placa USB denominada Makey Makey que, ao ser conectada ao computador do professor, emula entradas de um teclado e do mouse

O dispositivo ASU possibilita que as atividades educacionais sejam realizadas a partir do toque do estudante no próprio corpo ou no corpo de outros estudantes. É através da configuração de contatos elétricos em pisos no ambiente da sala de aula que os estudantes produzem um som. Quando um estudante em pé sobre um piso que possui um contato elétrico associado a um som (sinal) tocar a mão de um estudante ligado ao contato elétrico terra, o circuito é fechado (como um botão de liga e desliga) e o comando para a execução do som armazenado no computador é realizado. 
O processamento dos sons e seu gerenciamento são feitos em um computador na mesa do professor. Os sons gravados tocam em uma caixa de som ligada à saída de áudio do computador para que o professor e os estudantes possam ouvir as composições e performances coletivas. O acionamento dos sons depende da estrutura de contatos que será instalada para permitir, através do Makey Makey, que os estudantes possam usar seus corpos para interagir com o software (Figura 1).

\subsection{O Hardware "Makey Makey"}

O Makey Makey tem como característica inovadora poder fechar contato com materiais pouco condutivos como massa de modelar, frutas e o corpo humano. O Makey Makey é uma placa de circuito impresso USB que tem um processador ATMega32u4 rodando um Arduino Leonard firmware. Esta placa utiliza o protocolo Human Interface Device (HID) para se comunicar com o computador e para mandar mensagens e eventos como teclas apertadas e clicks e movimentos do mouse.

O Makey Makey possui 18 entradas digitais diferentes que funcionam como 18 botões. Ao se fechar o circuito entre uma entrada e o terra com um material minimamente condutivo, um sinal referente à entrada associada à determinada tecla ou ao controle do mouse é enviado para o computador como, por exemplo, barra de espaço ou click do botão direito do mouse. Dessa forma, o comando associado a cada tecla ou ao mouse é executado.

O custo do Makey Makey é baixo quando comparado ao de um computador. No mercado nacional ele pode ser encontrado por 249,00 reais (Robocore, 2015). Pela internet ele pode ser comprado no exterior por US\$ 50,00 (Joylabz, 2015).

\subsection{O software "soundplant"}

Duas opções foram consideradas para a escolha do software a ser usado: selecionar um software já disponível na web que se adequasse ao hardware ou desenvolver um software para interagir com o hardware da maneira desejada. As duas opções foram investigadas em paralelo. No entanto, o desenvolvimento de um software mostrou ser uma opção tecnicamente mais difícil, pois foram observados problemas de latência na produção sonora que não atendiam aos requisitos da atividade: o atraso entre o toque e a produção do som não pode ser perceptível. Foi escolhido então o soundplant que está disponível na web e tem uma versão gratuita. Este software permite endereçar arquivos de áudio para diferentes teclas do computador. Uma vez preparados os arquivos .wav, é só arrastá-los para as teclas desejadas. A partir desta configuração, toda vez que a tecla for acionada o som será executado.

\subsection{O piso}

Para evitar prender os estudantes a qualquer fio ou pedir que eles o segurassem, optou-se que o artefato usasse os contatos no chão: o estudante deve estar descalço ou de meias e pisar em um dos pisos que, disponíveis no chão da sala de aula, estão ligados aos fios que levam o sinal até o Makey Makey. O material escolhido para os pisos foi a placa EVA no formato quadrado de peças de quebra-cabeças (Figura 2). É importante que os pisos sejam de material isolante para evitar fechamento de circuito entre o piso e o chão como um falso terra, disparando assim o comando quando não há interação entre os estudantes. Cada piso é ligado por meio de um fio que segue pelo chão da sala sob fitas adesivas até uma entrada da placa Makey Makey (entrada de sinal ou terra). O fio que sai de cada piso EVA é preso passando-o por baixo do piso e chega à parte superior do piso para fazer contato com um papel laminado. Este papel laminado oferece uma 
maior área de contato dos pés dos estudantes com o fio. $\mathrm{O}$ papel laminado é preso no piso de EVA com garras metálicas e fita adesiva.

Com relação à disposição física, os pisos foram projetados de maneira a alternar um piso terra cercado de pisos de entrada. Desta forma é possível trocar o som produzido pelos estudantes que estão sobre os pisos terra. Nessa configuração algumas combinações não produzem som, como quando dois estudantes pisando terra e terra tocam um ao outro. Para facilitar a visualização do circuito, a cor preta foi reservada para os pisos terra; os demais pisos têm cores diferentes (Figura 2).

Os pisos de EVA são facilmente adquiridos no mercado ou já estão disponíveis em escolas por serem usadas como tapete para crianças. Fios, papel laminado e fita crepe ou isolante também são materiais de baixo custo e facilmente adquiridos.

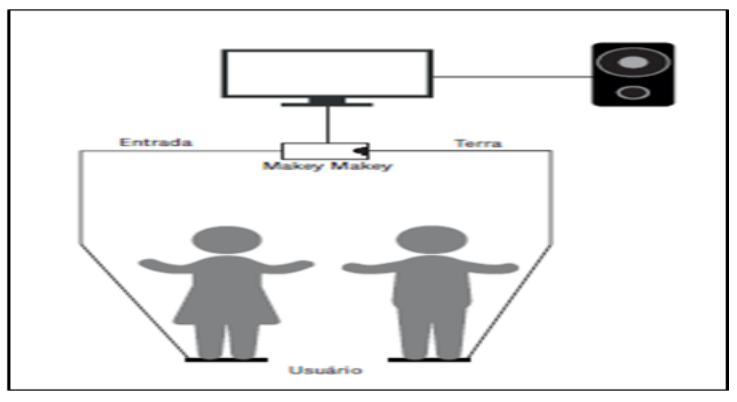

Figura 1

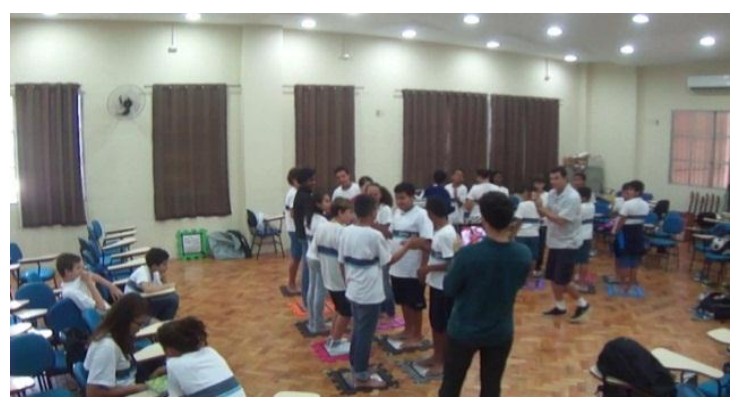

Figura 2. Atividade com o ASU

\section{Estudo de caso}

Com base no dispositivo ASU, foi realizado um estudo de caso exploratório com estudantes da Escola Municipal Ginásio Experimental Olímpico Juan Antonio Samaranch, situada em Santa Teresa no Rio de Janeiro, em abril e maio de 2015. O estudo de caso consistiu da realização de 3 atividades musicais sobre ritmo, melodia e acorde de forma a avaliar o artefato ASU quanto aos 6 primeiros requisitos elencados na seção 3.1. As 3 atividades foram realizadas ao longo de 8 aulas e, a cada aula, o pesquisador apresentava as novas atividades e seus exercícios e revia as atividades já trabalhadas. O professor da turma participou das atividades como assistente do pesquisador. Em um dia anterior ao início das 8 aulas, o pesquisador assistiu uma aula dada pelo professor para adequar o conteúdo das atividades aos temas estudados e ao espaço e ao tamanho da turma.

Os dados coletados para este estudo de caso são oriundos da observação direta do pesquisador. As atividades foram gravadas por um estudante de design em 2 câmeras, uma fixa e uma móvel, para posterior análise dos dados.

A avaliação do artefato nas atividades com os estudantes foi baseada na observação da desenvoltura que os estudantes tinham em experimentar o artefato. Os estudantes conseguiam produzir seus sons facilmente e conseguiam se concentrar nas atividades propostas? Os estudantes também preencheram questionários e foram gravadas entrevistas para apoiar a avaliação do uso e da aceitação do artefato pelos estudantes e professores.

Todas as atividades foram planejadas para conter três etapas: Imitação, Apreciação e Composição, que são parâmetros dos PCNs do MEC.

Atividade Rítmica: abordou o pulso e seus múltiplos na composição de ritmos e a apreciação de sons característicos (timbres) de diferentes instrumentos usados no 
acompanhamento rítmico da bateria (bumbo, caixa e contra tempo). A atividade rítmica utilizou 3 pares de pisos com um som de bateria para cada par (bumbo, caixa e contratempo). Os estudantes se revezaram nos pares e toda a turma pôde experimentar o artefato e produzir os sons solicitados (Execução) Três linhas rítmicas foram apresentadas aos estudantes apenas com o bater de palmas para, em seguida, elas serem executadas por meio do ASU (Apreciação). As três linhas rítmicas foram construídas (Composição) para acompanhar uma música, "Não mate a mata", que já vinha sendo trabalhada pelo professor com a turma em aulas anteriores ao estudo de caso. Também foi solicitado que a turma usasse o artefato para acompanhar o professor tocando um violão. Enquanto metade da turma cantava a música, a outra metade tocava o artefato e depois era feito um revezamento.

Atividade Melódica: abordou a escuta de diferentes instrumentos musicais (contrabaixo e violino) e a percepção da escala maior acompanhada da execução de melodias cíclicas (Ostinatos) entre grupos de estudantes. Nesta atividade foram distribuídos 10 pares de pisos referentes a 10 notas de violino (C3 a E4). Primeiramente foi solicitado aos estudantes que tocassem as notas, na sequência da mais grave a mais aguda, acompanhando o pulso dado por palmas feitas pelo pesquisador. Em seguida, 2 grupos, cada um com 5 pares de pisos, ficaram encarregados de criar sequências melódicas (Composição) para que a turma pudesse apreciar suas composições (Apreciação). As sequências eram executadas seguindo a pulsação feita pelo pesquisador e com as palmas para depois ser dada maior liberdade rítmica aos estudantes (Execução).

Atividade de Acordes: abordou a percepção da diferença entre nota musical e acorde, o conceito de acorde tocado com suas notas simultaneamente em sequência (arpejo) e o acompanhamento harmônico de melodias (Apreciação). Foi utilizada a mesma estrutura de 10 pares de pisos da atividade melódica. Cada grupo de 5 pares continha, separadamente, as 4 notas de uma tétrade (acorde com 4 notas), sendo uma nota por par de piso. O último par de pisos continha o acorde com as 4 notas tocadas simultaneamente. As notas do acorde eram então arpejadas pelos estudantes dos 4 primeiros pisos e, depois, o quinto par tocava o acorde completo dando a percepção harmônica do acorde em relação ao arpejo (Execução). Para esta atividade foram usados sons de piano. Primeiramente o ritmo era fixo com a pulsação e posteriormente foi dada maior liberdade aos estudantes. Em um segundo momento dessa atividade, mudou-se os sons dos pares de pisos. Um grupo de pisos continha 3 sons de acordes ( $\mathrm{C}$ tríade, $\mathrm{F}$ tríade e $\mathrm{G}$ tríade) distribuídos em 3 pares. Dois dos cinco pares não foram utilizados nessa variação da atividade 3 . O outro grupo de 5 pares tinha 5 sons de vibrafone contendo as notas da escala pentatônica de C (C3,D3,E3,G3,A3). O pesquisador solicitou que os estudantes de cada grupo criassem suas sequências livremente em relação às notas, acordes e ritmos (Composição) para que todos na turma pudessem ouvir uma melodia acompanhada de acordes.

\section{Resultados}

A avaliação do artefato ASU durante as 3 atividades mostra que ele atendeu aos 6 primeiros requisitos citados na seção 3.1 e que foram alvo deste estudo de caso.

Diferentes elementos do discurso musical foram trabalhados nas 3 atividades propostas como o ritmo, a melodia e os acordes e suas combinações. Foram utilizadas diferentes sonoridades como o som do bumbo, o som do vibrafone e o som do violino, entre outros. 
Todos os participantes aprenderam a produzir seus sons sem grandes dificuldades, podendo concentrar-se no discurso musical que era criado pela turma. Eles aprenderam quais pares de piso geravam sons, a pisar sobre o papel alumínio, a tirar som por contato na pele do colega ou sozinhos, caso um pé fosse colocado no chão.

$\mathrm{Na}$ primeira aula da atividade rítmica, seguir a pulsação para executar os ritmos da bateria foi o grande desafio para os estudantes. O som era produzido sem problemas, mas a atenção à escuta e a concentração para produzi-lo no momento certo ainda estavam sendo aperfeiçoadas pelos estudantes. $O$ andamento oscilava muito e os estudantes em sua maioria ainda organizavam suas estratégias para aprender a usar o ASU, inclusive criando coreografias. Por distração ou por movimentos imprecisos alguns erravam o toque nas mãos dos seus pares enquanto outros pisavam fora do piso ou tocavam nas roupas, casacos, camisa e não na pele dos seus pares; não fechando contato e, assim, não produziam sons. Alguns estudantes tinham dificuldade de controlar a ansiedade de tocar e acabavam acelerando o andamento do exercício. $\mathrm{O}$ pesquisador trabalhou mais detalhadamente a atenção dos participantes aos seus movimentos, aos movimentos de seus pares e aos respectivos sons produzidos. Com o passar do tempo a atenção aos movimentos, a precisão, e o ritmo melhoraram.

Nessa atividade rítmica o artefato também foi utilizado para acompanhar o professor da turma enquanto ele tocava o violão e um grupo de 10 estudantes cantavam a música Não Mate a Mata, evidenciando que o artefato pode ser conjugado com instrumentos musicais tradicionais. A disposição dos pisos permitiu liberdade de movimentos corporais para os estudantes e também estimulou a colaboração entre os estudantes que estão participando e outros que estão escutando a performance. Os estudantes criavam coreografias individuais ou coletivas para melhorar a precisão dos seus toques. Por exemplo, duas meninas que estavam tocando a linha da caixa foram auxiliadas por outro estudante que já tinha praticado a mesma linha. Este estudante se postou ao lado das duas colegas e com gestos ele indicava a hora certa de tocar a caixa como um regente. Rapidamente as colegas ajustaram o ritmo de sua execução. Outra dupla de meninos dançava e movimentava seus braços de maneira cíclica para encaixar os sons no momento certo da execução.

Na primeira aula da atividade 2, os estudantes já dominavam o uso do ASU. A atenção à escuta e a precisão dos movimentos necessários à execução do artefato aumentaram e a cada exercício realizado com sucesso a turma vibrava com muito entusiasmo. Em um primeiro momento, os ciclos melódicos solicitados foram executados junto da pulsação; depois, os estudantes tiveram liberdade de tocar ritmos que eram subdivisões do pulso. Gradativamente o pesquisador foi aumentando o número de ciclos de 1 para 2 por grupo. Desta forma cada grupo de estudantes, que já estava executando um ciclo melódico, tinha que pensar e compor outro ciclo para alternar com o primeiro. Os estudantes negociavam suas ideias de forma interessada e democrática evidenciando a colaboração e o engajamento alcançado por eles nas atividades.

A atividade 3 ofereceu aos estudantes a oportunidade de tocar arpejos, acordes e de mesclar melodias com um acompanhamento de acordes. O controle do pulso e dos ritmos por parte dos estudantes continuou a aumentar e o pesquisador deixou todos os alunos livres para executar os ritmos dos acordes e os ritmos das notas do vibrafone. $\mathrm{O}$ grupo dos acordes criou um ciclo com ritmos precisos enquanto o grupo das notas do vibrafone executava suas sequências que se mesclavam ao acompanhamento harmônico. 
Nas 3 atividades observamos que os estudantes utilizaram o corpo inclusive quando não estavam usando o artefato, colaboraram para executar os exercícios e foram instigados ao participarem ativamente das atividades em sala de aula.

Ao longo das 3 atividades observamos que a configuração do ASU em termos de quantidade e posicionamento dos pisos permite a troca rápida de estudantes nas atividades e em 1 minuto foi possível alternar 20 estudantes de cada vez nas atividades 2 e 3. A escolha da configuração com dois pisos produzindo um som também colaborou para o melhor aproveitamento do tempo e da quantidade de estudantes em sala de aula (35), além de intensificar a colaboração entre estudantes.

Como planejado, o uso do ASU possibilitou uma atividade em que todos os estudantes participaram produzindo sons ou cantando. Um revezamento possibilitou que todos fizessem os dois papéis.

Quanto à montagem do ASU observamos dois pontos a serem melhorados. Em menos de 3 ocasiões ao longo das 7 aulas, a conexão entre os fios e a placa e entre os fios e os pisos tinha mau contato e os sons do artefato não eram devidamente acionados. A solução para esta questão foi usar garras metálicas para fazer um contato com mais pressão e mais firmeza. Após a modificação para as garras metálicas não houve mau contato.

Os fios que conectam os pisos à placa, que variam entre 2 a 5 metros, se embaralham facilmente durante a montagem e precisam estar separados e bem enrolados para diminuir o tempo de montagem do artefato. Primeiramente o artefato foi montado e testado pelo pesquisador gastando-se 6 minutos por cada par de pisos em média. Após o tratamento dado aos fios, com a utilização de garras metálicas e carretilhas, o tempo caiu em $30 \%$. Apesar das melhorias realizadas ao longo das 7 aulas, cabe ressaltar que o ASU é um protótipo. Foge ao escopo desse trabalho investigar soluções de design que facilitem para o professor a montagem, desmontagem e transporte do artefato e uma melhor qualidade no uso do produto.

\section{Conclusão}

Nesse trabalho apresentamos o artefato ASU para apoiar as aulas de música no contexto do ensino fundamental. $O$ artefato foi avaliado por meio de um estudo de caso constituído de 3 atividades ao longo de 7 aulas em uma turma de $7^{\circ}$ ano com 35 estudantes. Esse estudo de caso mostra que um artefato digital que está de acordo com o cenário da computação ubíqua pode oferecer alternativas para reduzir as barreiras de execução sonora para os estudantes de música possibilitando um maior foco na aprendizagem dos conceitos a serem ensinados. O estudo de caso realizado mostra indícios de que o ASU pode ser usado como uma alternativa não excludente aos instrumentos musicais tradicionais na aula de música. $\mathrm{O}$ engajamento dos estudantes na atividade indica que a busca por soluções de ensino com novas tecnologias computacionais é válida e pode contribuir na dinâmica da sala de aula, integrando professores e estudantes em um ambiente de exploração e busca de conhecimento.

Trabalhos futuros incluem investigar o uso do artefato pelo professor, usar comunicação Bluetooth para reduzir a quantidade de fios e ampliar a faixa etária do perfil dos estudantes. Já está em andamento a avaliação destas 3 atividades em outras escolas.

\section{Agradecimentos}


Agradecemos à Escola Municipal Escola Municipal Ginásio Experimental Olímpico Juan Antonio Samaranch e ao professor de música Felipe Miranda, bem como os alunos que realizaram o estudo de caso e seus responsáveis.

\section{Referências bibliográficas}

Campbell, Patricia Shehan. (2008) Musician and Teacher. New York: W.W. Norton and Company, 2008.

Castro, Alberto; Menezes, Crediné. (2011) Aprendizagem Colaborativa com Suporte Computacional. Capítulo 9. Sistemas Colaborativos. Pimentel, Mariano, Fuks Hugo. (Organizadores) Ed. Elsevier/Campus, Rio de Janeiro.

Censo da educação básica: 2013 - resumo técnico. - Brasília: Instituto Nacional de Estudos e Pesquisas Educacionais Anísio Teixeira, 2014.

Cope, B., Kalantzis, M. (2009) Ubiquitous Learning

Dalcroze, E.J. (1921) Rhythm music and Education.G.P.Putnam's Sons New York.

Joylabz (2014) http://joylabz.com

Lei Federal 11.796/ 2008, de 18 de agosto de 2008. Diário Oficial da República Federativa do Brasil, Brasília, DF, n. 159, p. 1, 19 ago. 2008.

Makey Makey (2014) http://www.makeymakey.com/

OLPC (2005) http://one.laptop.org

Rhen, Zhimin; Mehra, Ravish; Coposky, Jason; Lin, Ming. (2012)Tabletop ensemble: touch-enabled virtual percussion instruments.I3D Proceedings of the ACM SIGGRAPH Symposium on Interactive 3D Graphics and Games.

Richardson, Will. (2012) Why school?: How Education Must Change When Learning and information Are Everywhere TED Conferences (September 10, 2012)

Rosen, D., Schmidt, E., Kim, Y. (2013) Utilizing music technology as a model for creativity development in K-12 education. C\&C 13: Proceedings of the $9^{\text {th }}$ ACM Conference on Creativity and Cognition.

Robocore (2014) http://www.robocore.net

Shamrock, Mary. (2009) "Orff- Schulwerk: An Integrated Method." Music Educator's Journal 83 (Maio, 1997): 41-44. JSTOR. University of Arizona Music Library., Tucson, AZ. 3 Fevereiro 2009 <http://www.jstor.org/stable/3399024/>.

Soundplant (2014) http://soundplant.org/

UCA (2007)http://www.uca.gov.br/institucional/

Volpe, G., Varni, G., Mazzarino, B., Addessi, Anna.(2012)BeSound: Embodied Reflexion for Music Education in Childhood. IDC 2012 SHORT PAPERS 12th-15th June, Bremen, Germany

Weiser, M. (1991) The computer for the twenty-first century. Scientific American, 65(3):94-104.

Zhang, C.; Shen, Li.;Wang D.; Tian, F.; Wang, H.(2011) CoolMag: A Tangible Interaction Tool to Customize Instruments for Children in Music Education.UbiComp'11 / Beijing, China

Zhou,Y., Percival,G, Wang,X., Wang., Zhao,S. (2011) - MOGCLASS: Evaluation of a Collaborative System of Mobile Devices for Classroom Music Education of Young Children School of Computing (SoC), National University of Singapore- CHI-2011 